\title{
The 2015 revision of the Jones criteria for the diagnosis of acute rheumatic fever: implications for practice in low-income and middle-income countries
}

\author{
Andrea Beaton, ${ }^{1}$ Jonathan Carapetis $^{2}$
}

\begin{abstract}
${ }^{1}$ Children's National Health
System, Cardiology,

Washington DC, USA

${ }^{2}$ Telethon Kids Institute,

University of Western Australia, and Princess Margaret Hospital for Children, Subiaco, Western Australia, Australia
\end{abstract}

\section{Correspondence to}

Dr Jonathan Carapetis, Telethon Kids Institute, University of Western Australia, Princess Margaret Hospital for Children, 100 Roberts Rd, Subiaco, WA 6008, Australia; jonathan.carapetis@ telethonkids.org.au

Accepted 5 August 2015

\section{ABSTRACT}

The Jones criteria has longed served as the primary guideline for diagnosing acute rheumatic fever (ARF). However, since the first iteration in 1944, the global epidemiology of ARF and our knowledge regarding the variability of its presentation have changed. In 2015, the American Heart Association took on an ambitious and successful revision, which accounts for these changes. For the first time, the criteria consider the risk within a population and offer two separate diagnostic pathways that prioritise specificity among those at low risk and sensitivity among those at moderate/high risk. Echocardiography is now recommended in all patients with suspected or confirmed ARF, and subclinical carditis can fulfil a major criterion for ARF in all populations. Finally, new and specific criteria are provided for the diagnosis of ARF recurrences. These changes improve the diagnosis of ARF among moderate/high-risk populations and re-establish the Jones criteria as the international gold standard for ARF diagnosis. It is our hope that they will also serve as a catalyst in the global community to increase advocacy, improve case detection, and invest in new research techniques that could ultimately control global ARF in our lifetimes.

\section{INTRODUCTION}

Acute rheumatic fever (ARF) killed more US youths (aged 5-20 years) than any other condition during the early part of the 20 th century. ${ }^{1}$ The care and convalescence of patients with ARF became the focus of entire institutions, like the House of Good Samaritan in Boston, Massachusetts. There, Dr T Duckett Jones dedicated his career to the study of this devastating condition. ${ }^{2}$ The most indelible of his contributions was the development of the first clinical criteria for the diagnosis of ARF. ${ }^{3}$ These criteria, known as the 'Jones Criteria' remained the benchmark for ARF diagnosis for over 50 years.

But much has changed over the last half-century. Development and widespread deployment of echocardiography has improved our ability to diagnose and understand rheumatic carditis. The epidemiology of ARF has shifted, with near-eradication in most of the developed world and disease persistence in low-resource nations. And, study of ARF in these low-resource settings has shown unaccountedfor variability in its clinical presentation. Over this time, the American Heart Association (AHA) has published four revisions to Dr Jones' criteria. The latest carefully accounts for these shifts, ensuring Dr Jones' name and work remain relevant into the next century.

\section{REVISING THE STANDARD}

In the late 19th century, improvements in housing and hygiene, which continued into the 20th century and were accompanied by identification of streptococcus and the advent of penicillin, led to the virtual disappearance of ARF in the USA and other high-income nations. ${ }^{4}$ The AHA championed the use of antibiotic prophylaxis and stewarded the Jones criteria, which remained an important, living document throughout the latter half of the 20th century. The decline in ARF in the USA motivated revisions of the Jones criteria to prioritise high specificity at the cost of lowered sensitivity. ${ }^{5-7}$ While these changes were appropriate for high-income, low-prevalence countries, concerns began to surface that the 1992 revision of the Jones criteria lacked sufficient sensitivity for use in highprevalence regions. ${ }^{8-10}$

This sentiment was most acute in the Pacific, where indigenous populations continue to experience some of the highest rates of ARF in the world. Concerns culminated in Australia and New Zealand deciding, for the first time, to publish ARF diagnostic guidelines that diverged from the Jones criteria, ${ }^{11-13}$ while WHO released its own version, providing guidance in areas where the Jones criteria were lacking, such as how to use them to diagnose ARF recurrences. ${ }^{14}$ Other countries ${ }^{15}{ }^{16}$ followed suit, and the Jones criteria risked becoming a relic of history.

However, in 2012, AHA took on another revision, and made the historic decision to include prominent authors living and/or working in highprevalence regions. The resulting guidelines, published in 2015, acknowledge the importance of including pretest probability in weighing sensitivity versus specificity, and include separate guidelines for low-risk (prioritising sensitivity) and moderate-tohigh-risk (prioritising specificity) populations. ${ }^{17}$ This revision also embraces the improved diagnostic capacity offered by echocardiography, recommending its use in all populations, when available, for the diagnosis of rheumatic carditis. In light of its recalibration towards the changing presentation and demographics of ARF, the 2015 revision will ensure the Jones criteria are re-established as the international gold standard for ARF diagnosis.

\section{JONES CRITERIA: MAJOR CHANGES AND IMPLICATIONS FOR LOW-INCOME AND MIDDLE-INCOME COUNTRIES \\ Current diagnostic criteria}

Despite over a half-century of research, no confirmatory test is available for ARF, and diagnosis 
continues to rely on a constellation of clinical features. Following the precedent set by Dr Jones, the AHA criteria categorise manifestations of ARF into major and minor criteria. ${ }^{3}$ Since $1965,{ }^{6}$ and through the 2015 revision, ${ }^{17}$ a first episode of ARF is diagnosed when a patient has evidence of recent streptococcal infection in addition to either two major or one major and two minor criteria. It is the major and minor criteria, and the diagnosis of recurrences, that have been the subject of ongoing debate.

The 2015 updates (table 1) address three main changes in its diagnostic criteria: risk stratification, echocardiographic detection of subclinical carditis and joint manifestations. Each is discussed below, along with the rationale behind the changes.

\section{Separation into low-risk and moderate/high-risk populations}

The burden of ARF is distributed unequally around the globe. High-income countries have seen a near eradication of disease. Low-income/low-resource countries, or poorer populations within wealthy countries, have seen very little change in ARF incidence. ${ }^{18}$ In fact, as the majority of the world's population lives in high-prevalence regions, ARF and rheumatic heart disease (RHD; ARF's most devastating complication) remain the leading cause of early cardiovascular morbidity and mortality. Recent data estimates that at least 34.2 million people currently live with RHD, with over 340000 annual deaths. ${ }^{19}$

The epidemiology in high-prevalence areas also differs from historical ARF data. Compared with the seasonal outbreaks previously seen in industrialised countries, it is common in endemic regions to see hyperendemic disease patterns with high rates of year-round presentation. Moreover, there are data from high-prevalence settings such as Australia ${ }^{8} 2021$ that the clinical manifestations of ARF, in particular joint presentations and peak fever, may be substantially less dramatic, and thus less clinically obvious, compared with those seen in low-risk settings.

Table 1 Summary of the 2015 Jones criteria $^{17}$

\begin{tabular}{|c|c|c|}
\hline \multicolumn{3}{|c|}{ Jones criteria for the diagnosis of ARF } \\
\hline & $\begin{array}{l}\text { Low-risk population } \\
\text { ARF incidence } \leq 2 \text { per } 100000 \\
\text { school-aged children or all-age } \\
\text { RHD prevalence of } \leq 1 \text { per } 1000 \\
\text { population year }\end{array}$ & $\begin{array}{l}\text { Moderate/high-risk } \\
\text { population } \\
\text { Children not clearly from } \\
\text { a low-risk population }\end{array}$ \\
\hline \multicolumn{3}{|l|}{ Major criteria } \\
\hline Carditis & Clinical and/or subclinical* & $\begin{array}{l}\text { Clinical and/or } \\
\text { subclinical }^{*}\end{array}$ \\
\hline \multirow[t]{4}{*}{ Arthritis } & Polyarthritis & $\begin{array}{l}\text { Monoarthritis, } \\
\text { polyarthritis and/or } \\
\text { polyarthralgia }\end{array}$ \\
\hline & Chorea & Chorea \\
\hline & Erythema marginatum & Erythema marginatum \\
\hline & Subcutaneous nodules & Subcutaneous nodules \\
\hline \multicolumn{3}{|l|}{ Minor criteria } \\
\hline Carditis & Prolonged PR intervalt & Prolonged PR interval† \\
\hline Arthralgia & Polyarthralgia & Monoarthralgia \\
\hline Fever & $\geq 38.5^{\circ} \mathrm{C}$ & $\geq 38^{\circ} \mathrm{C}$ \\
\hline $\begin{array}{l}\text { Markers of } \\
\text { inflammation }\end{array}$ & $\begin{array}{l}\text { Peak ESR } \geq 60 \mathrm{~mm} \text { in } 1 \mathrm{~h} \text { and/or } \\
\mathrm{CRP} \geq 3.0 \mathrm{mg} / \mathrm{dL}\end{array}$ & $\begin{array}{l}\text { Peak ESR } \geq 30 \mathrm{~mm} \text { in } 1 \mathrm{~h} \\
\text { and/or } C R P \geq 3.0 \mathrm{mg} / \mathrm{dL}\end{array}$ \\
\hline \multicolumn{3}{|c|}{$\begin{array}{l}\text { Changes compared with the } 1992 \text { revision }^{7} \text { are highlighted in bold. } \\
\text { *Subclinical carditis: Seen only on echocardiography without ausculatory findings. } \\
\text { †Accounting for age variability and only if carditis NOT counted as a major criteria. } \\
\text { ARF, acute rheumatic fever; CRP, C reactive protein; ESR, erythrocyte sedimentation } \\
\text { rate; RHD, rheumatic heart disease. }\end{array}$} \\
\hline
\end{tabular}

These considerations, plus evidence that strict adherence to the 1992 Jones criteria resulted in missed ARF diagnosis, ${ }^{8}$ led to the development of the Australian ARF diagnostic guidelines. ${ }^{11}$ The Australian guidelines were the first to consider high-risk and low-risk populations separately, emphasising high sensitivity among those at greatest risk and high specificity for those at lower risk. The 2015 Jones criteria revision has embraced this risk-stratified approach. Importantly, compared with the Australian guidelines which provide a definition for high risk, the 2015 revision defines low risk (ARF incidence $<2$ per 100000 school-aged children per year or an all-age prevalence of RHD of $\leq 1$ per 1000 population per year), and states that children not clearly from a low-risk ARF population should be considered at moderate-to-high risk (moderate and high are treated equally) and considered under the modified diagnostic pathway. ${ }^{17}$ Practically, clinicians will likely find it easier to decide if an individual is at low risk (based on socioeconomic factors) compared with high, improving the uniformity and ease of choosing a diagnostic pathway.

\section{Addition of subclinical carditis as a major manifestation}

Clinical carditis has classically been defined as an audible murmur consistent with aortic or mitral regurgitation. ${ }^{7}$ In 2000 , the AHA ARF working group acknowledged that interest was growing in the importance of subclinical carditis, or clinically silent valvular involvement only detectable through echocardiography, as an indicator of $\mathrm{ARF}^{22}$ But, it concluded that at that time there was insufficient evidence to include subclinical carditis as a major or a minor manifestation. Additionally, they highlighted that use of echocardiography to detect subclinical carditis could lower the specificity of the Jones criteria, and lead to overdiagnosis of ARF, and overuse of long-term penicillin prophylaxis as a result of the diagnosis. ${ }^{22}$

During the past decade many studies have shown the substantial prevalence and significance of subclinical carditis among patients with ARF, leaving little doubt as to its importance in ARF diagnosis. A 2007 meta-analysis that included 23 studies from five continents demonstrated that patients with ARF showed a weighted pooled prevalence of subclinical carditis of

Table 2 A Comparison of past and current recommendations for evaluation of carditis in suspected and confirmed acute rheumatic fever (ARF)

\begin{tabular}{|c|c|c|c|c|}
\hline & $\begin{array}{l}\text { Clinical } \\
\text { carditis as a } \\
\text { MAJOR } \\
\text { manifestation }\end{array}$ & $\begin{array}{l}\text { Preform } \\
\text { echo in all } \\
\text { confirmed } \\
\text { cases of } \\
\text { ARF }\end{array}$ & $\begin{array}{l}\text { Perform } \\
\text { echo in all } \\
\text { suspected } \\
\text { cases of } \\
\text { ARF }\end{array}$ & $\begin{array}{l}\text { Subclinical } \\
\text { carditis as a } \\
\text { MAJOR } \\
\text { manifestation }\end{array}$ \\
\hline $\begin{array}{l}\text { Jones } \\
1992^{7}\end{array}$ & Yes & No & No & No \\
\hline $\begin{array}{l}\text { WHO } \\
2001^{14}\end{array}$ & Yes & No & No & No \\
\hline $\begin{array}{l}\text { New } \\
\text { Zealand } \\
2008^{13}\end{array}$ & Yes & Yes & Yes & $\begin{array}{l}\text { Yes; all } \\
\text { populations }\end{array}$ \\
\hline $\begin{array}{l}\text { India } \\
2008^{15}\end{array}$ & Yes & Yes & No & No \\
\hline $\begin{array}{l}\text { Australia } \\
2012^{11}\end{array}$ & Yes & Yes & Yes & $\begin{array}{l}\text { Yes; high-risk } \\
\text { populations }\end{array}$ \\
\hline $\begin{array}{l}\text { Jones } \\
2015^{17}\end{array}$ & $\begin{array}{l}\text { Yes; unless } \\
\text { disproven by } \\
\text { echo }\end{array}$ & Yes & Yes & $\begin{array}{l}\text { Yes; all } \\
\text { populations }\end{array}$ \\
\hline
\end{tabular}


Table 3 Echocardiographic criteria for the diagnosis of subclinical carditis $^{31}$

\begin{tabular}{|c|c|}
\hline $\begin{array}{l}\text { Pathological mitral regurgitation } \\
\text { (meets all four criteria) }\end{array}$ & $\begin{array}{l}\text { Pathological aortic regurgitation } \\
\text { (meets all four criteria) }\end{array}$ \\
\hline Seen in at least two views & Seen in at least two views \\
\hline Jet length $\geq 2 \mathrm{~cm}$ in at least one view & Jet length $\geq 1 \mathrm{~cm}$ in at least one view \\
\hline Peak velocity $>3 \mathrm{~m} / \mathrm{s}$ & Peak velocity $>3 \mathrm{~m} / \mathrm{s}$ \\
\hline Pansystolic jet in at least one envelope & $\begin{array}{l}\text { Pandiastolic jet in at least one } \\
\text { envelope }\end{array}$ \\
\hline \multicolumn{2}{|c|}{$\begin{array}{l}\text { Diagnosis of subclinical carditis is based upon fulfilment of criteria for pathological } \\
\text { mitral and/or pathological aortic regurgitation. While common morphological features } \\
\text { of rheumatic carditis are provided, and support the diagnosis of ARF, they are less } \\
\text { commonly seen in isolation during ARF and cannot alone be used to diagnose ARF. }{ }^{17} \\
\text { ARF, acute rheumatic fever. }\end{array}$} \\
\hline
\end{tabular}

$16.8 \%$. Importantly, $44.7 \%$ of these patients showed worsening of valvular involvement over time. ${ }^{23}$ These findings led to the inclusion of echocardiography for the evaluation of patients with suspected or confirmed ARF and the addition of subclinical carditis as a major manifestation for all populations in the 2008 New Zealand guidelines ${ }^{13}$ and high-risk populations in the 2012 Australian guidelines. ${ }^{11}$

The 2015 Jones revision made similar recommendations: either clinical or subclinical carditis qualifies as a major manifestation in low-risk and high-risk populations (table 2). The criteria recommend that, when possible, all patients with confirmed or suspected ARF undergo echocardiography to evaluate for carditis, with those who are negative on first evaluation undergoing repeated study to assess for evolving cardiac disease. ${ }^{17}$ Diagnosis of subclinical carditis is made based on specific recommendations for pathological Mitral Regurgitation/ Aortic Regurgitation (MR/AR) (table 3). Additionally, a normal echocardiogram can rule out a diagnosis of carditis made through clinical auscultation (improving specificity). ${ }^{17}$

\section{Joint manifestations}

As arthritis/arthralgia can be seen in a wide spectrum of diseases, inclusion of different forms of joint involvement in the Jones criteria has been the subject of much debate over the years. This factor complicates ARF evaluation because many patients self-medicate with widely available over-the-counter anti-inflammatory medications, which effectively treat the arthritis/arthralgia associated with ARF, often before presentation for formal diagnosis.

It is increasingly clear that classic migratory polyarthritis (previously considered the only major joint manifestation) is not the only form of joint involvement that can occur in patients with ARF. In high-risk populations, restricting the major criteria for joint involvement to only migratory polyarthritis results in missed cases of ARF. ${ }^{8}$ Recent studies in high-risk populations have shown that aseptic monoarthritis is an important manifestation of ARF. ${ }^{20} 24-26$ In Australia, monoarthritis was seen in 16$18 \%$ of children who were diagnosed with ARF based on fulfilment of other criteria. ${ }^{8}$ Additionally, a retrospective chart review found an additional 27 out of 75 children with monoarthritis who would have met criteria for ARF had monoarthritis been included as a major criterion. Of these, over half $(55 \%)$ went on to develop either ARF or RHD-indicating that the initial diagnosis should probably have been ARF. ${ }^{8}$

Given this evidence, the 2015 Jones criteria revision now includes polyarthritis, monoarthritis and polyarthralgia as major criteria and monoarthralgia as a minor criterion in moderate-risk and high-risk populations. ${ }^{17}$ These changes are in line with the current Australian ${ }^{11}$ and New Zealand ${ }^{13}$ guidelines (table 4). No change has been made to the diagnosis of joint involvement in low-risk populations, and as always, there is an emphasis on ensuring other differential diagnoses for joint involvement have first been excluded. ${ }^{17}$

\section{Minor criteria}

The 2015 revision made additional modifications to its minor criteria-also to improve the sensitivity of ARF diagnosis in moderate-prevalence to high-prevalence populations. First, the fever cut-off (which has varied over the years) was lowered to $38.0^{\circ} \mathrm{C}$, based primarily on evidence from the Australian Aboriginal population of poor sensitivity for ARF with higher temperature requirements. ${ }^{8}$ Additionally, based on expert opinion, the erythrocyte sedimentation rate cut-off was lowered to $>30 \mathrm{~mm} / \mathrm{h}$ in moderate-risk to high-risk populations (as compared with $>60 \mathrm{~mm} / \mathrm{h}$ in low-risk populations), consistent with the Australian ARF guidelines. ${ }^{11}$

\section{ARF recurrences}

It is well recognised that patients with a history of ARF are at high risk for recurrences and progression of cardiac disease. However, specific diagnostic criteria for an ARF recurrence have been missing from previous iterations of the Jones criteria. The 1992 revision merely commented within the text that a presumptive diagnosis of recurrence could be made if there was evidence of recent streptococcal infection and, 'a single major or several minor manifestations'. ${ }^{7}$ Newly, the 2015 revision provides direct guidance, requiring that two major, one major and two minor, or three minor criteria be met in a patient with a

Table 4 A Comparison of past and current recommendations for evaluation of joint manifestations for the diagnosis of ARF

\begin{tabular}{|c|c|c|c|c|}
\hline & Polyarthritis & Monoarthritis & Polyarthralgia & Monoarthralgia \\
\hline Jones $1992^{7}$ & Major & Not included & Minor & Not included \\
\hline WHO $2001^{14}$ & Major & Not included & Minor & Not included \\
\hline New Zealand $2008^{13}$ & Major & $\begin{array}{l}\text { Major (in the setting of prior NonSteroidal } \\
\text { Anti-Inflammatory Drugs (NSAID) use) }\end{array}$ & Minor & Not included \\
\hline India $2008^{15}$ & Major & Not included & Minor & Not included \\
\hline Australia $2012^{11}$ & Major & Major (high-risk populations) & $\begin{array}{l}\text { Major (high-risk populations) and minor } \\
\text { (low-risk populations) }\end{array}$ & Minor (high-risk populations) \\
\hline Jones $2015^{17}$ & Major & $\begin{array}{l}\text { Major (moderate/high-risk populations), } \\
\text { not included in low-risk populations }\end{array}$ & $\begin{array}{l}\text { Major (moderate/high-risk populations), } \\
\text { minor (low-risk populations) }\end{array}$ & $\begin{array}{l}\text { Major (moderate/high-risk populations), } \\
\text { not included in low-risk populations }\end{array}$ \\
\hline
\end{tabular}


reliable past history of ARF/RHD and documentation of a recent streptococcal infection. ${ }^{17}$ Recognising that diagnostic overlap can occur, even in patients with established RHD, emphasis remains on excluding more likely diagnoses, in particular when only minor manifestations are present. ${ }^{17}$

\section{POTENTIAL IMPACT ON THE GLOBAL BURDEN AND CONTROL OF ARF AND RHD \\ Increased global advocacy}

There is an imbalance between the global burden of ARF/RHD and the importance placed on it by the public health community and governments in many high-prevalence regions. The publication of the 2015 Jones criteria provides an opportunity to rebalance that emphasis through renewed advocacy and educational efforts. At the highest levels, this would translate into national governments raising the priority level of ARF/RHD within their health agendas and establishing national programmes for ARF/ RHD prevention. The best comprehensive national programmes would include a countrywide ARF/RHD registry (making these diseases reportable conditions); an assured supply of penicillin of reliable quality; training for front-line healthcare providers on the diagnosis and treatment of streptococcal disease, ARF and RHD; and community education and awareness campaigns linking streptococcal disease to ARF/RHD. Data from Cuba suggest that such comprehensive programmes could significantly reduce disease burden within a decade. ${ }^{27}$

Supporting materials from non-governmental organisations are increasingly available to support governmental initiatives. Interactive, computer-based modules (WiRED International), which have recently become publicly available, provide practical, high-quality lessons to improve healthcare-worker, teacher and student education. The TIPS handbook created in partnership between the World Heart Federation and RhEACH (Rheumatic Heart Disease: Evidence, Advocacy, Communication, Hope), provides a powerful and practical advocacy tool to support the development and strengthening of national $\mathrm{ARF} / \mathrm{RHD}$ programmes.

\section{Increased case detection}

The 2015 Jones criteria also has the potential to help answer one of the most puzzling and important questions in RHD research: Where are all the children with ARF? Echocardiographic screening studies have uncovered that 1.5$5.6 \%$ of children in low-resource areas demonstrate evidence of latent $\mathrm{RHD},{ }^{28}$ but almost none of them remembers a history of ARF. $^{29}$ Even among adults presenting with advanced RHD to a tertiary care centre in Uganda, none recalled a childhood history consistent with ARF. ${ }^{30}$ No one fully understands why presentation rates of ARF remain relatively low in many areas where RHD is endemic. It is possible that ARF masquerades as other high-prevalence diseases (ie, malaria in Africa), that ARF presents atypically and escapes detection (eg, monoarthritis in the Pacific), that ARF is clinically silent or that children and caregivers who do not recognise the significance of ARF findings simply never present for diagnosis. Most likely, a combination of these factors contributes to the gap between detection and reporting.

Currently, most cases of ARF in developing countries are missed. This comes at great human and financial cost, because untreated ARF most often results in advanced RHD. Solving this problem will continue to be challenging in low-resource settings with limited access to comprehensive primary healthcare, diagnostic testing for streptococcal disease or detailed medical records. However, the 2015 Jones criteria offers a single set of globally agreed upon criteria that could provide a starting point, ensuring a uniform system for diagnosis and data aggregation across research sites.

\section{Increased research potential}

Regardless of how this revision improves the accuracy of ARF diagnosis, it will remain imperfect because diagnosis still relies on a clinical diagnostic algorithm. In the absence of a confirmatory test, there will always be potential for imperfect specificity and overinclusive diagnoses, as well as imperfect sensitivity and missed cases of ARF. There remains a need to use modern immunophenotyping and genotyping techniques to improve our understanding of ARF pathogenesis, and potentially identify biomarkers that could augment the accuracy of the Jones criteria. The 2015 Jones criteria have the potential to increase case detection, with more internationally accepted guidelines providing phenotypical uniformity that can speed these advancements, and confer generalisability to the findings.

In summary, the 2015 revision has re-established the Jones criteria as the pivotal guidance document for ARF diagnosis in all settings. The guidelines stay true to the approach of Dr Jones by maintaining high specificity for ARF in low-risk populations, but recognise changing global needs and epidemiology by providing more sensitive guidelines for use in moderate/high-risk settings. It is our hope that the global community will capitalise on this important advancement and the publicity it brings by working to increase global advocacy, improve case detection and invest in new research techniques that could ultimately control global ARF in our lifetimes.

Contributors $\mathrm{AB}$ and $\mathrm{JC}$ contributed equally to the drafting of this manuscript. Competing interests None declared.

Provenance and peer review Commissioned; internally peer reviewed.

\section{REFERENCES}

1 Armstrong D, Wheatley G. Studies in rheumatic fever. New York: Metropolitan Life Insurance Company, 1944.

2 Bland EF. Rheumatic fever: the way it was. Circulation 1987;76:1190-5.

3 Jones TD. The diagnosis of rheumatic fever. JAMA 1944;126:481-4.

4 Gordis L. The virtual disappearance of rheumatic fever in the United States: lessons in the rise and fall of disease. T. Duckett Jones memorial lecture. Circulation 1985; 72:1155-62.

5 [No authors listed]. Jones Criteria (modified) for guidance in the diagnosis of rheumatic fever. Public Health Rep 1956;71:672-4.

6 [No authors listed]. Jones Criteria (revised) for guidance in the diagnosis of rheumatic fever. Circulation 1965;32:664-8.

7 Guidelines for the diagnosis of rheumatic fever. Jones Criteria, 1992 update. Special writing group of the committee on rheumatic fever, endocarditis, and Kawasaki disease of the council on cardiovascular disease in the young of the American Heart Association. JAMA 1992;268:2069-73.

8 Carapetis JR, Currie BJ. Rheumatic fever in a high incidence population: the importance of monoarthritis and low grade fever. Arch Dis Child 2001;85:223-7.

9 Stewart T, McDonald R, Currie B. Use of the Jones Criteria in the diagnosis of acute rheumatic fever in an Australian rural setting. Aust N Z J Public Health 2005;29:526-9.

10 Saxena A. Diagnosis of rheumatic fever: current status of Jones Criteria and role of echocardiography. Indian J Pediatr 2000;67:S11-14.

11 National Heart Foundation of Australia (RF/RHD Guidelines Development Working Group) and the Cardiac Society of Australia and New Zealand. Diagnosis and management of acute rheumatic fever and rheumatic heart disease in AustraliaAn evidence-based review. 2006. http://www.heartfoundation.org.au/ SiteCollectionDocuments/Diagnosis-Management-Acute-Rheumatic-Fever.pdf

12 RHDAustralia (ARF/RHD Writing Group), National Heart Foundation of Australia, Cardiac Society of Australia and New Zealand. The Australian guideline for prevention, diagnosis, and management of acute rheumatic fever and rheumatic heart disease. 2nd edn. Casuarina, Australia: RHDAustralia, 2012.

13 Atatoa-Carr P, Lennon D, Wilson N. Rheumatic fever diagnosis, management, and secondary prevention: a New Zealand guideline. N Z Med J 2008;121:59-69.

14 World Health Organization. Rheumatic fever and rheumatic heart disease: report of a WHO expert consultation, Geneva, 29 October-1 November, 2001. WHO technical series 923 2004. http://www.who.int/entity/cardiovascular_diseases/ resources/trs923/en/. 
15 Saxena A, Kumar RK, Gera RP, et al. Consensus guidelines on pediatric acute rheumatic fever and rheumatic heart disease. Indian Pediatr 2008;45:565-73.

16 Sociedade Brasileira de Cardiologia. Brazilian guidelines for the diagnosis, treatment and prevention of rheumatic fever. Arq Bras Cardiol 2009;93:3-18.

17 Gewitz MH, Baltimore RS, Tani LY, et al. Revision of the Jones Criteria for the diagnosis of acute rheumatic fever in the era of doppler echocardiography: a scientific statement from the american heart association. Circulation 2015;131:1806-18.

18 Seckeler MD, Hoke TR. The worldwide epidemiology of acute rheumatic fever and rheumatic heart disease. Clin Epidemiol 2011;3:67-84.

19 GBD 2013 Mortality and Causes of Death Collaborators. Global, regional, and national age-sex specific all-cause and cause-specific mortality for 240 causes of death, 1990-2013: a systematic analysis for the global burden of disease study 2013. Lancet 2015;385:117-71.

20 Parks T, Kado J, Colquhoun S, et al. Underdiagnosis of acute rheumatic fever in primary care settings in a developing country. Trop Med Int Health 2009;14:1407-13.

21 Sanyal SK, Thapar MK, Ahmed SH, et al. The initial attack of acute rheumatic fever during childhood in north india; a prospective study of the clinical profile. Circulation 1974;49:7-12.

22 Ferrieri P. Proceedings of the Jones Criteria workshop. Circulation 2002;106:2521-3.
23 Tubridy-Clark M, Carapetis JR. Subclinical carditis in rheumatic fever: a systematic review. Int J Cardiol 2007;119:54-8.

24 Cann MP, Sive AA, Norton RE, et al. Clinical presentation of rheumatic fever in an endemic area. Arch Dis Child 2010;95:455-7.

25 Noonan S, Zurynski YA, Currie BJ, et al. A national prospective surveillance study of acute rheumatic fever in Australian children. Pediatr Infect Dis J 2013;32: e26-32.

26 Harlan GA, Tani LY, Byington CL. Rheumatic fever presenting as monoarticular arthritis. Pediatr Infect Dis I 2006;25:743-6.

27 Nordet $\mathrm{P}$, Lopez $\mathrm{R}$, Duenas $\mathrm{A}$, et al. Prevention and control of rheumatic fever and rheumatic heart disease: the Cuban experience (1986-1996-2002). Cardiovasc J Afr 2008; 19:135-40.

28 Roberts K, Colquhoun S, Steer A, et al. Screening for rheumatic heart disease: current approaches and controversies. Nat Rev Cardiol 2013;10:49-58.

29 Beaton A, Okello E, Lwabi P, et al. Echocardiography screening for rheumatic heart disease in Ugandan schoolchildren. Circulation 2012;125:3127-32.

30 Zhang W, Mondo C, Okello E, et al. Presenting features of newly diagnosed rheumatic heart disease patients in Mulago Hospital: a pilot study. Cardiovasc J Afr 2013:24:28-33.

31 Remenyi B, Wilson N, Steer A, et al. World Heart Federation criteria for echocardiographic diagnosis of rheumatic heart disease - an evidence-based guideline. Nat Rev Cardiol 2012;9:297-309. 